\title{
Anomalous left circumflex artery: a case report
}

\section{Ivana Jovanovska Hristova*, Magdalena Otljanska}

JZU Univerzitetska klinika za Kardiologija, Skopje, Makedonija
KEYWORDS: coronary artery anomaly, coronary angiography, cardiomyopathy. CITATION: Cardiol Croat. 2016;11(12):633. | DOI: http://dx.doi.org/10.15836/ccar2016.633

*ADDRESS FOR CORRESPONDENCE: Ivana Jovanovska Hristova, JZU Univerzitetska klinika za Kardiologija, Vodnjanska 17, 1000 Skopje, Makedonija. / E-mail: cenetata86@yahoo.com

ORCID: Ivana Jovanovska Hristova, http://orcid.org/0000-0002-3752-345X

Magdalena Otljanska, http://orcid.org/0000-0003-0190-9710

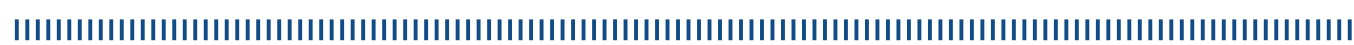

Background: The general population, just like the majority of the patients in the angiography laboratory, have a predictable anatomy and presentation of the coronary arteries. Only 1.3\% of the patients in a number of 126.595 have anatomical anomalies of the coronary arteries. Of the three main coronary arteries, the circumflex artery presents with a great variant of length and distribution. There is gender predominance, study reports findings in favor of the male population (73 cases, 57male/16 female). There are three types of anomalies of the left circumflex artery (ALCX), among which the most common are the adjacent ostia in the right coronary sinus..$^{1-3}$

Case report: We present a clinical case of a 59-year-old female, who presented to a tertiary facility due to a first onset of chest pain who was evaluated for an underlying coronary artery disease. Physical examination showed non-specific signs. She had a previous history of hypertension. The diagnostic workout included: laboratory, electrocardiography, echocardiography and coronary angiography. The electrocardiogram had features of left bundle branch block. The heart ultrasound showed global reduction of the LV systolic function, impaired diastolic function which is a consequence of a long life arterial hypertension. Coronary angiography findings: anomalous left circumflex artery (ALCX) adjacent ostia in the right coronary sinus. We did a one month follow up during that period of time she was treated with: ACE inhibitor, beta-blocker, loop diuretic, aldosterone antagonist and aspirin

Conclusion: The coronary artery anomalies are most often an accidental finding in the catheterization laboratory. Most variations are benign with a variable clinical presentation and prognosis. The anatomical variations in the left circumflex artery are relatively common as in our case the adjacent ostia in the right coronary sinus.
RECEIVED:

November 10, 2016

ACCEPTED:

November 20, 2016

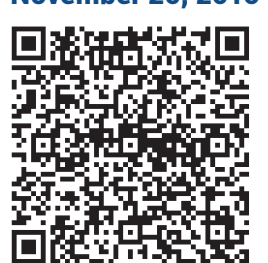

LITERATURE IIIIIIIIIIIIIIIIIIIIIIIIIIIIIIIIIIIIIIIIIIIIIIIIIIIIIIIIIIIIIIIIIIIIIIIIIIIIIIIIIIIIIIIIIIIIIIIIIIII

1. Yamanaka 0, Hobbs RE. Coronary artery anomalies in 126,595 patients undergoing coronary arteriography. Cathet Cardiovasc Diagn. 1990;21(1):28-40. DOI: http://dx.doi.org/10.1002/ccd.1810210110

2. Vilallonga JR. Anatomical variations of the coronary arteries: I. The most frequent variations. Eur J Anat. 2003; 7 Suppl 1:29-41.

3. Wilkins CE, Betancourt B, Mathur SV, Massumi A, De Castro MC, Garcia E, et al. Coronary artery anomalies: a review of more than 10,000 patients from the Clayton Cardiovascular Laboratories. Tex Heart Inst J. 1988;15(3):166-73. PubMed: https://www.ncbi.nlm.nih.gov/pubmed/15227247 